\title{
16 APPLICATION OF DATA FROM FIELD- AND LABSCALE MICROBIOLOGICAL STUDIES FOR TREATMENT OF PHENOLIC LEACHATE IN NATURAL SYSTEMS
}

\author{
Ain Heinaru \\ Eeva Heinaru \\ Ene Talpsep \\ Jaak Truu
}

Institute of Molecular and Cell Biology, University of Tartu, 23 Riia Str.,Tartu,

Estonia

\begin{abstract}
The phenol-rich leachate from semi-coke mounds formed as a by-product of oil-shale processing is discharged via channels and rivers Kohtla and Purtse into the Baltic Sea without any treatment. The leachate from processed oil shale contains several organic and inorganic compounds (oil fractions, sulphides, polycyclic aromatic hydrocarbons). The impact of leachate on microbiological characteristics of river water and sediment as well as on abundance, activity and structure of biodegradative consortia have been studied. The metabolic and genetic diversity of phenol-utilizing bacteria was characterized. Pollution markedly altered all aspects of the studied microbial diversity. The structure and functioning of the bacterial communities changed significantly along the river and revealed remarkable adaptation to phenolic compounds in environment. The results demonstrate multiplicity of catabolic types of degradation of phenol and $p$-cresol and the existence of characteristic assemblages of species and specific genotypes among the strains isolated from the polluted river water.
\end{abstract}

\section{KEYWORDS}

Phenolic leachate, bacteria, biodegradation, oil-shale industry.

\section{INTRODUCTION}

Oil shale industry has created a serious pollution problem in the north-eastern part of Estonia. The phenol-rich leachate (from 300 up to $10000 \mathrm{~m}^{3}$ day $^{-1}$ ) from semi-coke mounds formed as a by-product of oil-shale processing is discharged via channels and rivers Kohtla and Purtse into the Baltic Sea without any treatment. The leachate from processed oil shale contains several organic and inorganic compounds (oil fractions, sulphides, polycyclic aromatic hydrocarbons). In average $62,2 \mathrm{~kg}$ volatile phenolic compounds are entering into river water daily, while maximum discharged amounts exceed $350 \mathrm{~kg}$ day $^{-1}$. 
The wastewater from semi-coke depository has $\mathrm{pH}$ in the range 10.2-12.3, COD of 2500-3600 $\mathrm{mg} \mathrm{O}_{2} \mathrm{l}^{-1}$, and concentration of total phenols in the range 500-700 $\mathrm{mg} \mathrm{l}^{-1}$, while the phenolic compounds form approximately $9-10 \%$ of the COD of the leachate. According to the HPLC data the volatile phenols in the leachate contain mainly phenol (from 33.2 to $44.2 \%$ ) and cresols (from 16.1 to $40.6 \%$ ), while the concentration of resorcinol, methylresorcinols and dimethylphenols do not exceed $22.4 \%$.

We have been studying the impact of leachate from semi-coke mounds on microbiological characteristics of river water and sediment since 1993 in the north-eastern part of Estonia. These studies comprise of research on microbial community structure of the polluted sites with special emphasize on abundance, activity and structure of biodegradative consortia as well as biochemistry and regulation of metabolic routs of biodegradative bacteria.

\section{LABORATORY STUDIES OF METABOLIC AND GENETIC DIVERSITY OF PHENOL-UTILIZING BACTERIA}

The metabolic and genetic diversity of phenol-utilizing 119 bacterial strains isolated from the rivers polluted by ash dump leachate in Kohtla Järve, Estonia, has been studied (1). Of 18 different bacterial species identified, $82 \%$ belong to the genus Pseudomonas. Comparison of genetic (phenol monooxygenase/PMO/ and catechol 2,3-dioxygenase/C23O/ gene probes) and biochemical (PMO, C23O, catechol 1,2-dioxygenase and protocatechuate 3,4dioxygenase activities) data with species of isolated bacteria shows that in different polluted regions of the rivers different Pseudomonas fluorescens biotypes and $P s$. mendocina are predominant and they harbor characteristic genetic traits. The incidence of plasmid-bearing bacteria is much higher in phenol-polluted waters (up to $81 \%$ of the strains) than in nonpolluted river waters $(38 \%)$. We found three main types of induction of aromatic ringfission pathways among the isolated phenol-growing bacteria which also grow on p-cresol. Some new bacterial isolates, such as Ps. fluorescens strains PC20 and PC24 revealed even higher biodegradation capabilities of volatile phenols in leachate than laboratory-selected phenol-growing bacteria.

Further 39 phenol- and p-cresol-degrading isolates were studied (2). Species identification by BIOLOG GN analysis revealed 21 strains of Pseudomonas fluorescens (4, 8 and 9 of biotypes A, C and G, respectively), 12 of Pseudomonas mendocina, four of Pseudomonas putida biotype A1, one of Pseudomonas corrugata and one of Acinetobacter genospecies 15 . Computer-assisted analysis of rep-PCR fingerprints clustered the strains into groups with good concordance with the BIOLOG GN data. Three main catabolic types of degradation of phenol and $p$-cresol were revealed. Type I, or meta-meta type (15 strains), was characterized by meta cleavage of catechol by catechol 2,3-dioxygenase (C230) during the growth on phenol and $p$-cresol. These strains carried $\mathrm{C} 230$ genes which gave PCR products with specific $x y l$ E-gene primers. Type II, or ortho-ortho type (13 strains), was characterized by the degradation of phenol through ortho fission of catechol by catechol 1,2-dioxygenase (C12O) and $p$-cresol via ortho cleavage of protocatechuic acid by protocatechuate 3,4-dioxygenase (PC340). These strains carried phenol monooxygenase gene which gave PCR products with pheA-gene primers. Type III, or meta-ortho type (11 strains), was characterized by the degradation of phenol by $\mathrm{C} 23 \mathrm{O}$ and p-cresol via the protocatechuate ortho pathway by the induction of PC34O and this carried C23O genes which gave PCR products with C23O-gene primers, but not with specific $x y l E$-gene primers. In type III strains phenol also induced the $p$ cresol protocatechuate pathway, as revealed by the induction of $p$-cresol methylhydroxylase. These results demonstrate multiplicity of catabolic types of degradation of phenol and $p$ - 
cresol and the existence of characteristic assemblages of species and specific genotypes among the strains isolated from the polluted river water.

Three bacterial strains $P$. mendocina PC1, P. fluorescens PC18 and P. fluorescens PC24 were selected for study of accumulation of key catabolic intermediates during degradation of phenol, $p$-cresol and benzoate in two-substrate batch cultivations (3). According to sequence analysis of $16 \mathrm{~S}$ rRNA genes the strains belonged to different monophyletic clusters of Pseudomonas. It was shown that if the substrates were degraded from mixtures using either catechol meta, catechol ortho or catechol ortho and protocatechuate ortho pathways, then both substrates were catabolised simultaneously without the accumulation of intermediates. Exceptionally, degradation of phenol and benzoate via catechol ortho pathway caused irreversible accumulation of cis, cis-muconate without detectable effect on simultaneous consumption of substrates. When the substrates were degraded from mixtures through meta and ortho catabolic pathways, the sequential consumption of substrates (diauxic growth) was observed due to the reversible accumulation of catabolic intermediates $p$-hydroxybenzoate or catechol. The regulation of parallel catabolic pathways by the accumulation of catabolic intermediates revealed quantitative character. Only in the strain PC18 the accumulation of $p$ hydroxybenzoate during growth on phenol-p-cresol mixture seems to be directly genetically regulated because phenol also induces catabolic pathway for $p$-cresol degradation. Partial sequencing of $p$-cresol methylhydroxylase genes of the strains PC18 and PC24 showed considerable differences.

\section{FIELD STUDIES OF MICROBIAL COMMUNITES OF POLLUTED SITES}

Spatial dynamics, abundance and the biodegradation potential of aquatic microbial communities were studied during the period from November 1993 until September 1995 in the Kohtla-Järve region of north-eastern Estonia (4). General trends in bacterial population density profiles indicated that the microbial community including the heterotrophic, lipolytic, denitrifying bacteria and biodegradative bacteria (phenol, $m$-toluate, benzoate, salicylate, camphor, naphthalene and heptane degrading bacteria) were strongly inhibited in the highly polluted waters with oil shale ash leachate effluent and the bacterial numbers increased as the pollution load decreased. Microbial communities revealed significant adaptation to phenolic compounds in the environment, particularly the phenol and benzoate degraders. Distribution of phenol degraders showed remarkable similarity with the heterotrophic, lipolytic and denitrifying bacterial distribution pattern. The biodegradation potential rose throughout the river Kohtla and Purtse revealing a high natural selfpurification process. The data analysis underlined the importance of oxygen as a positive factor and high $\mathrm{pH}$ as negative factor for river heterotrophic bacterial community.

The comparison of numbers of phenol- and benzoate-degrading bacteria in the water and sediments showed that high contamination concentrations were lethal for bacterial communities in the water while sediment communities survived. The high numbers of bacteria capable of biodegradation in the river sediments compared to water bacteria revealed the accumulation of contaminants in the sediments. Several culture-independent methods, applying DNA directly extracted from semi-coke and sediments, such as BOX-PCR, Ribosomal Intergenic Spacer Analysis (RISA), Randomly Amplified Polymorphic DNA (RAPD) and Denaturing Gradient Gel Electrophoresis (DGGE) were used to compare the communities and to determine their diversity. The lowest diversity was discovered in the channel around semi-coke mounds, the highest in the river sediments. Few dominant bacterial populations were characteristic for the semi-coke communities and the channel sediment. The 
DGGE analysis revealed the succession of microbial communities along water discharge system starting from semi-coke mound to the Kohtla River.

The species composition of a degradative bacterial community varies depending on the concentration of pollutants. The majority of isolated phenol degraders belonged to the genus Pseudomonas, among them $P$. fluorescens biotype $\mathrm{C}$ and $P$. mendocina showed the best adaptation to phenolic pollution.

During the period 29.05-02.06.1995 the removal efficiency of volatile phenols was near $100 \%$ in river water. The decrease in the amount of phenols in the water was very fast along the first couple of kilometers in the beginning of the channel area; approximately half of the released volatile phenols were removed. An approximately twofold reduction in the degradation rate of volatile phenols occurred after the channel joins the Kohtla River. An average degradation rate for volatile phenols was $1 \mathrm{mg} \mathrm{L}^{-1}$ day $^{-1}$ for the whole river system. The calculations for the entire study period (May-September 1995) based on data from Kiviter, Ltd. yielded in removal efficiency of $85 \%$ for volatile phenols, and $30 \%$ for total phenols.

\section{CONCLUSIONS}

Natural systems are increasingly being used for treating municipal, industrial and agricultural effluents. In order to achieve maximal pollution attenuation in these systems the physical, chemical and biological conditions that affect transformations and treatment efficiency should be optimal. As a prerequisite for the biodegradation of phenolic compounds in the leachate the presence of active and abundant bacterial community is needed. It should be possible to apply the results from field-and labscale microbiological studies given above for constructing and operating natural treatment systems for treatment of phenolic leachates.

Results of our work allow to draw the conclusion that the environmental problems created by the oil shale industry wastewaters could be solved by treatment of this water in natural systems.

\section{REFERENCES}

1. Heinaru E, Talpsep E, Linnas A, Heinaru A, Stottmeister U (1997). Metabolic and genetic diversity of phenol-utilizing bacteria as an enhancer of natural biodegradation in polluted waters. Oil Shale 14, 454-468

2. Heinaru, E., Truu, J., Stottmeister, U., Heinaru, A. (2000). Three types of phenol and p-cresol catabolism in phenol- and p-cresol-degrading bacteria isolated from river water continuously polluted with phenolic compounds. FEMS Microbiol. Ecol. 31, 195-205.

3. Heinaru, E., Viggor S., Vedler E. , Truu, J., Merimaa M., Heinaru, A. (2001). Reversible accumulation of p-hydroxybenzoate and catechol determines the sequential decomposition of phenolic compounds in mixed substrate cultivation in pseudomonads. FEMS Microbiol. Ecol. 37, 1-11.

4. Talpsep E, Heinaru E, Truu J, Laht T, Heinaru A, Wand H, Stottmeister U (1997). Functional dynamics of microbial populations in waters contaminated with phenolic leachate. Oil Shale 14, 435-453 